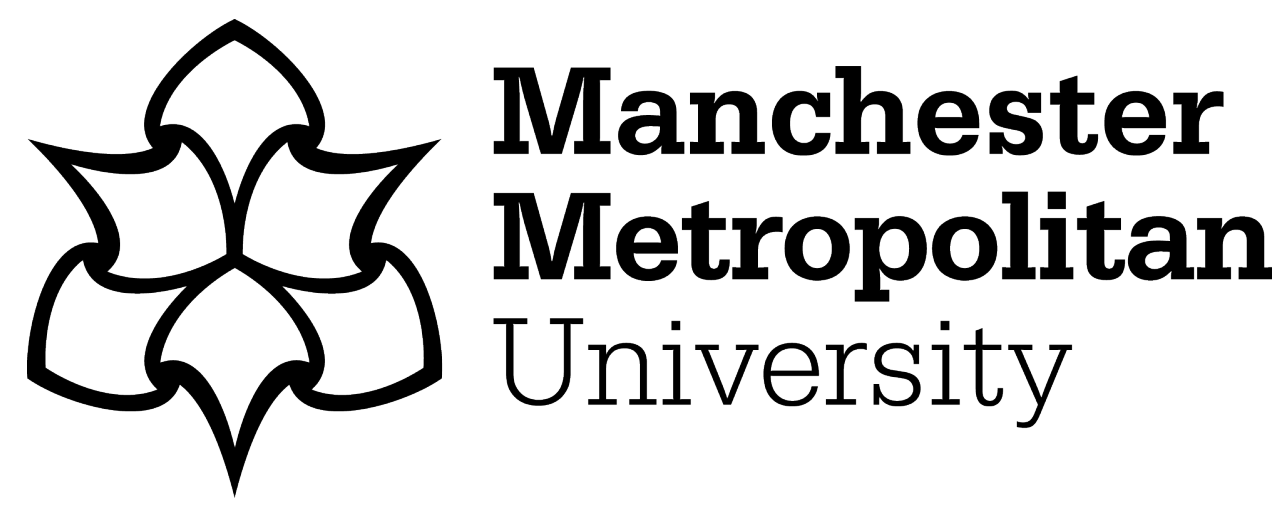

Gorgadze, Aleksei, Sinitsyna, Anastasia, Trabskaya, Julia and Bala, To'neill ORCID logoORCID: https://orcid.org/0000-0002-8215-2803 (2021) The impact of new affective components on museum visitor retention: the context of major city event using SEM and CTree. International Journal of Event and Festival Management, 12 (2). pp. 203-223. ISSN 1758-2954

Downloaded from: https://e-space.mmu.ac.uk/628625/

Version: Accepted Version

Publisher: Emerald

DOI: https://doi.org/10.1108/ijefm-11-2020-0071

Usage rights: Creative Commons: Attribution-Noncommercial 4.0

Please cite the published version 


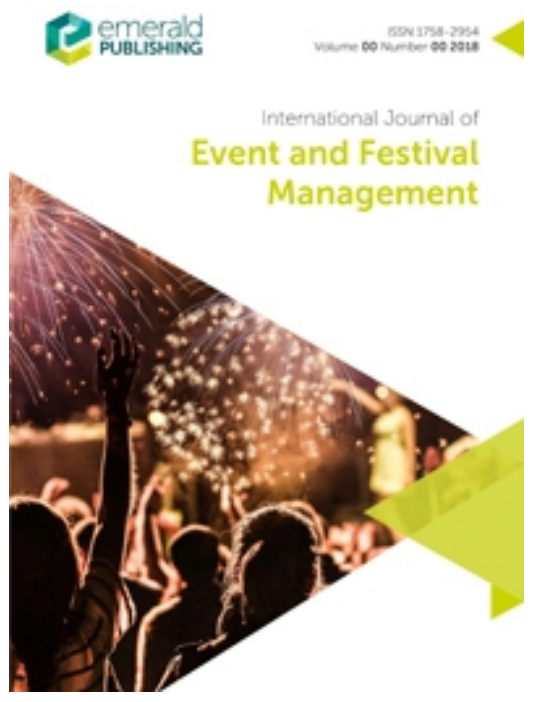

\section{The Impact of New Affective Components on Museum Visitor Retention: the Context of Major City Event using SEM and CTree}

\begin{tabular}{|r|l|}
\hline Journal: & International Journal of Event and Festival Management \\
\hline Manuscript ID & IJEFM-11-2020-0071.R2 \\
\hline Manuscript Type: & Research Paper \\
\hline Keywords: & $\begin{array}{l}\text { Museum, Revisit Intention, Perceived Value, Conditional Inference Tree, } \\
\text { Structural Equation Model, Affective Components }\end{array}$ \\
\hline
\end{tabular}

\section{SCHOLARONE $^{\text {Im }}$ Manuscripts}


Table I. CFA for Attraction, Fitness, Uniqueness and Atmosphere

\begin{tabular}{|c|c|c|c|c|}
\hline Construct & Question & $\begin{array}{l}\text { Question } \\
\text { Mean }\end{array}$ & $\begin{array}{l}\text { Question } \\
\text { Standard } \\
\text { Deviation } \\
\text { SD }\end{array}$ & $\begin{array}{l}\mathrm{R} \text { square } \\
\text { for factor } \\
\text { loading }\end{array}$ \\
\hline \multirow[t]{4}{*}{ Attractiveness } & This museum improves my mood & 3.44 & 0.81 & 0.44 \\
\hline & $\begin{array}{l}\text { This place has many interesting objects that I } \\
\text { would like to observe. }\end{array}$ & 3.48 & 0.85 & 0.13 \\
\hline & I enjoy every moment here. & 3.13 & 0.95 & 0.55 \\
\hline & I would like to spend more time here. & 2.81 & 1.04 & 0.28 \\
\hline \multirow[t]{7}{*}{ Atmosphere } & $\begin{array}{l}\text { The spaciousness of the museum has helped } \\
\text { me to enjoy the Long Night of Museums. }\end{array}$ & 3.37 & 0.87 & 0.37 \\
\hline & $\begin{array}{l}\text { I appreciated the opportunity to interact with } \\
\text { other visitors at the event. }\end{array}$ & 2.73 & 1.16 & 0.14 \\
\hline & $\begin{array}{l}\text { Creativity of the event has helped me to enjoy } \\
\text { staying in this place. }\end{array}$ & 3.41 & 0.83 & 0.51 \\
\hline & $\begin{array}{l}\text { The light effects used in the event have helped } \\
\text { me to enjoy staying here. }\end{array}$ & 2.67 & 1.26 & 0.44 \\
\hline & $\begin{array}{l}\text { The sound effects used in the event have } \\
\text { helped me enjoy to staying here. }\end{array}$ & 3.06 & 1.12 & 0.51 \\
\hline & $\begin{array}{l}\text { The surroundings of the museum (park, } \\
\text { garden, street outside the museum) have all } \\
\text { helped me to enjoy the event. }\end{array}$ & 3.59 & 0.73 & 0.39 \\
\hline & $\begin{array}{l}\text { I appreciated the opportunity to not only } \\
\text { watch but also to participate in the event. }\end{array}$ & 3.03 & 1.06 & 0.33 \\
\hline \multirow[t]{3}{*}{ Uniqueness } & This place has a unique style. & 3.62 & 0.65 & 0.56 \\
\hline & $\begin{array}{l}\text { This place is not any different from other } \\
\text { cultural organisations. }\end{array}$ & 3.26 & 0.97 & 0.35 \\
\hline & $\begin{array}{l}\text { I do not know any other place in Saint } \\
\text { Petersburg where I can have this much fun. }\end{array}$ & 1.53 & 0.83 & 0.17 \\
\hline \multirow[t]{5}{*}{ Fitness } & $\begin{array}{l}\text { My lifestyle matches the atmosphere of this } \\
\text { place. }\end{array}$ & 2.79 & 1.06 & 0.21 \\
\hline & I find this place appealing. & 3.34 & 0.91 & 0.59 \\
\hline & I do not find this place relatable. & 3.26 & 1.07 & 0.09 \\
\hline & This place needs additional maintenance. & 2.88 & 1.09 & 0.10 \\
\hline & I found it difficult to get to this place. & 3.3 & 1.1 & excluded \\
\hline
\end{tabular}




\begin{tabular}{|l|l|l|l|l|}
\hline & $\begin{array}{l}\text { Overcrowding was interfering with my } \\
\text { experience at the event. }\end{array}$ & 3.3 & 1.01 & 0.08 \\
\cline { 2 - 5 } & $\begin{array}{l}\text { This place needs additional personnel to keep } \\
\text { it organised. }\end{array}$ & 3.63 & 0.79 & 0.021 \\
\cline { 2 - 4 } & $\begin{array}{l}\text { The employees are very polite and ready to } \\
\text { answer any questions. }\end{array}$ & 3.68 & 0.66 & excluded \\
\hline
\end{tabular}

Note. Initial questions were asked in Russian and later for research purposes were translated into English

\section{English}


Figure 1. Theoretical framework for predicting revisit intentions. $338 \times 190 \mathrm{~mm}(96 \times 96$ DPI) 


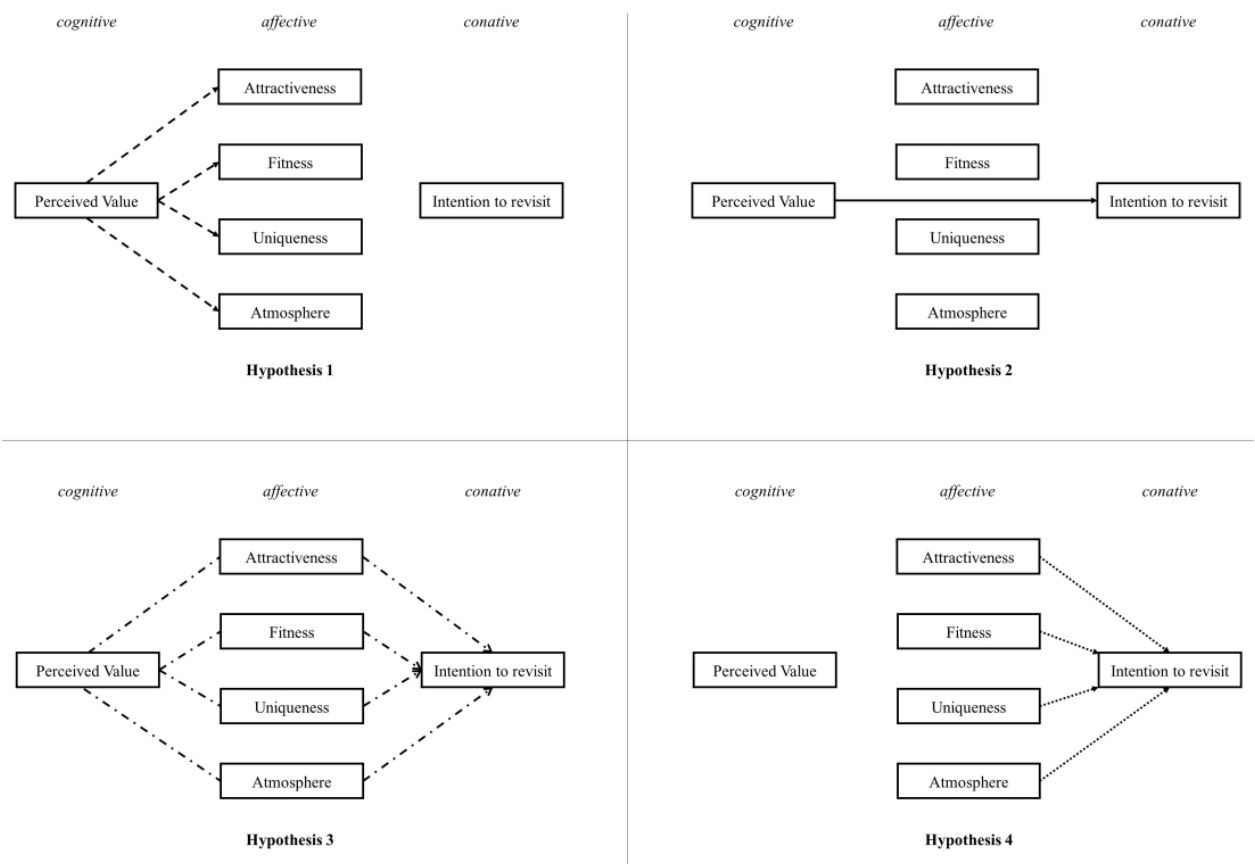

Figure 2. Hypothesis visualization.

$1000 \times 700 \mathrm{~mm}(96 \times 96$ DPI) 


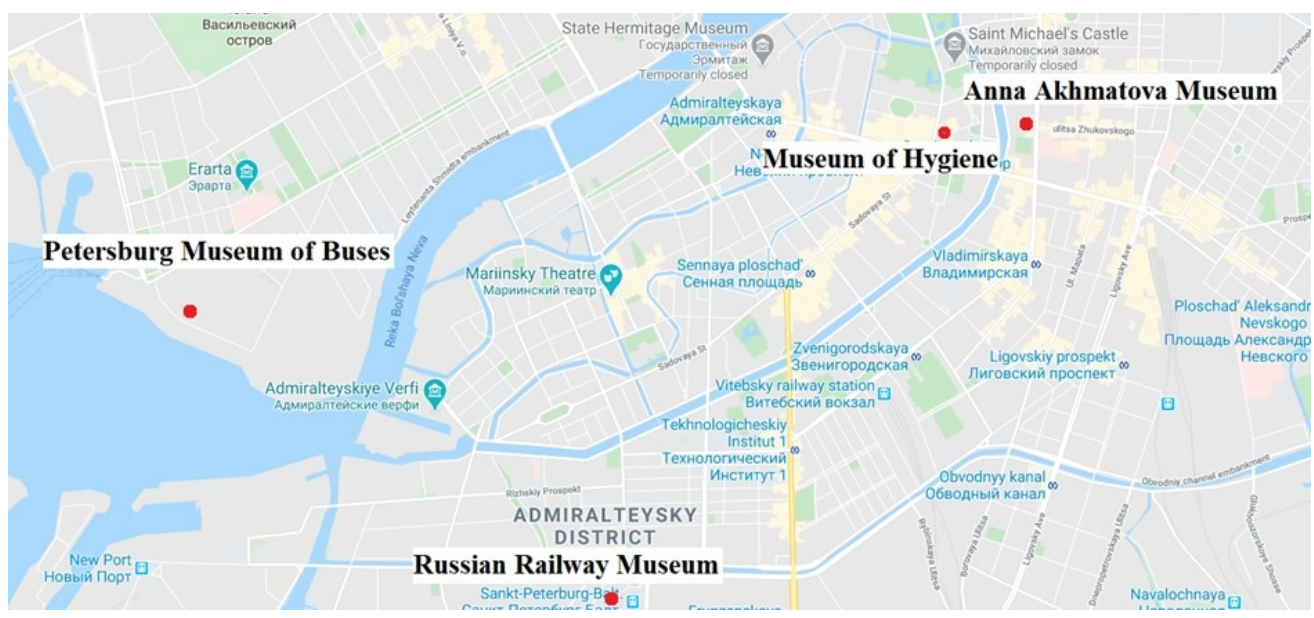

Figure 3. Museums, on the territory of which a visitor survey was organised.

$$
159 \times 73 \mathrm{~mm}(150 \times 150 \mathrm{DPI})
$$


cognitive affective conative

Figure 4. Structural Model. Note: Coeficients of models are above and below the arrows significant at $10 \%$; $* *$ significant $5 \%$; *** significant at $1 \%$. Source: own calculations based on Survey results. 


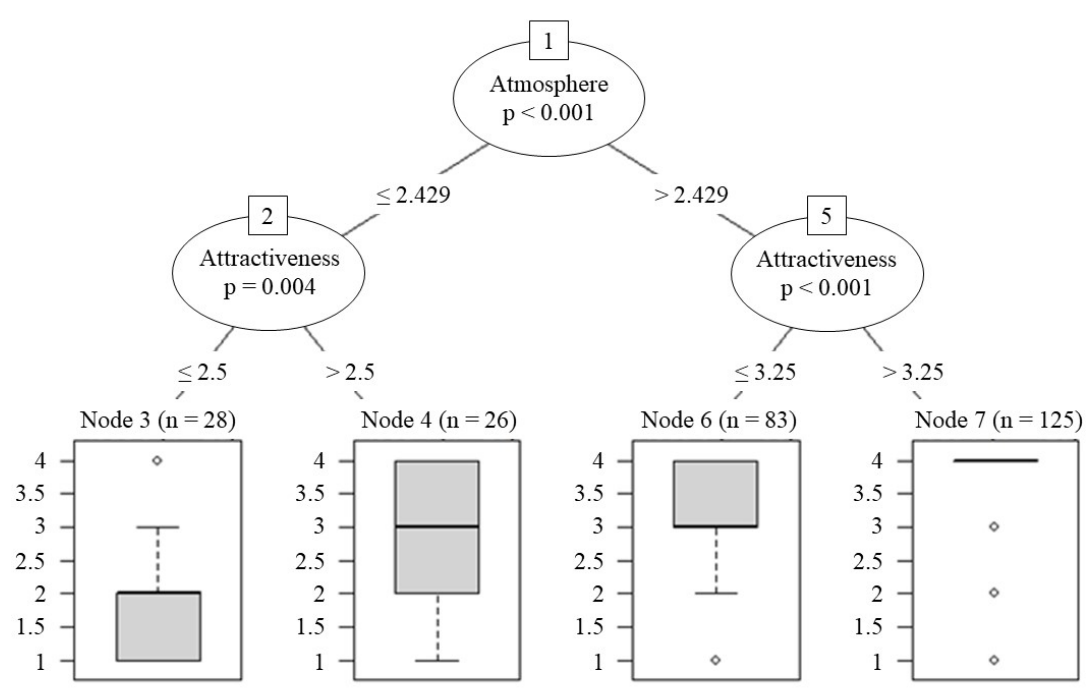

Figure 5. Conditional Inference Tree. $338 \times 190 \mathrm{~mm}(96 \times 96$ DPI) 


\title{
The Impact of New Affective Components on Museum Visitor Retention: the Context of Major City Event using SEM and CTree
}

\author{
A Case Study of the Long Night of Museums in Saint Petersburg
}

\begin{abstract}
Purpose: The main purpose of this study is to examine the relationship between range of affective components that have an impact on the revisit intention of museums visitors, in the context of a major city event. The study reveals the most significant factors the affect decision making by applying the findings to a Structural Equation Model (SEM) and Conditional Inference Tree (CTree).

Design/methodology/approach: The paper utilises face-to-face survey research at the 'Long Night of Museums' event in Saint Petersburg, 298 questionnaires were completed on the night of the event. The empirical part of the research is based on the SEM and interpreted by using the CTree. The SEM model measures the direct and indirect influence of the cognitive and affective components, the CTree enables the testing of both component and the joint effect they both produce.
\end{abstract}

Findings: This study shows a strong indirect correlation between the cognitive component of the major city event, and the revisit intention of museum visitors. When focusing on affective components, both the SEM and the CTree demonstrated that attractiveness and atmosphere are revealed to be the most impactful elements regarding visitor retention and repeat custom. The research allows for a deeper understanding of visitor behaviours, intentions and their decision-making processes.

Originality/value: This is an original study which aims to integrate the impact of the perceived value of the cognitive component and a new range of affective elements regarding a museum retention in the context of a major city event. The study includes newly developed dimensions of perceived value, as well as a unique focus on affective dimensions such as - atmosphere and attraction. Another point of originality is provided by using a CTree, which captures an in depth understanding of the intention formation process. This study provides an opportunity to advance our understanding of visitor decisionmaking processes.

Practical implications: The results of the study allow museum managers to understand how to create repeat custom amongst visitors, by appreciating the importance of participation in major city events, and the role that attraction and atmosphere play when creating intention for repeat visit. The research has uncovered which dimensions are the most important to visitors, and as a result, these particular dimensions should be thoroughly developed by museums in future in order to attract and repeat visits. This study has demonstrated the practical implications for museums participating in city events. When considering policy makers, this particular research provides an opportunity to develop recommendations for future city events, as well as using the CTree to assess and predict the effectiveness of visitor behaviour.

Keywords: Long Night of Museums, Major City Event, Museum, Revisit Intention, Perceived Value, Conditional Inference Tree (CTree), Structural Equation Model (SEM), Experience, Atmosphere, Attractiveness.

Paper type: Research paper 


\section{Introduction}

Recently museums have been challenged by many new trends, including new audiences, high levels of competition, co-creation patterns, globalisation, and a digital shift towards a virtual world. Furthermore, there have been shifts in leisure consumption and competition for leisure time (Juniu, 2010; O'Donnell and Barber, 2021; Williams, 2002). Additionally, museums have found themselves under further pressure caused by the Covid-19 lockdown. To overcome these multiple challenges, museums are forced to understand how to operate and attract new visitors as well as engage for repeat visits. It is increasingly important for museums to understand which factors influence consumer behaviour and most importantly visitor retention.

One solution may be to investigate whether museums need to work collaboratively in order to create new experiences and repeat visitors. This study will review the 'Long Night of Museums' event in Saint Petersburg, and determine whether events such as these are beneficial to the long-term success of museums. Major city events organised in collaboration with museums have become a recent popular phenomenon. The "Long Night of Museums" event is a shining example of such a collaboration. Several museums take part in the event by creating unique programmes, and by applying creative tools in order to increase the attractiveness of their museum. In turn this has been shown to improve the attractiveness of the major city event overall. Thus, museums can be seen as an important influence when appealing to visitor attendance at these collaborative events (Codignola and Mariani, 2017). The Museum Night is an unique phenomenon to study. First of all, this event takes place in many countries around the world. Naturally, measuring the influence of this event on consumer behaviour is appealing to practitioners and policy makers in many countries. Countries and cities invest considerable funds into these events; however, the impact of these events is still largely unmeasured. The global footprint of the event under study also helps generalise the results of the research. Being a special global phenomenon, scientific literature mostly lacks studies dedicated to the Museum Night which is where the current study fills a gap.

It remains unclear as to whether museums can utilise any benefits from major city events, furthermore, whether major city events play a role in regards to the attractiveness of museums towards visitors (Komarac et al., 2019). Various factors influence the impact on museum visitor behaviour at major city events. Firstly, when a major city event has its own reputation and promotion, some visitors may have experience of visiting previously. If a particular museum is popular, it transfers its reputation and characteristics over to participating museums, thus benefiting a museum that may be lesser known. Secondly, when a participating museum prepares for major city event, it creates a special program and extra activities thus changes in some way. Lastly, the paper mentions the congruity of effects produced by major city events that change the functioning of museums as a result.

This research seeks to address the following questions: what is the effect of cognitive and affective components on the intention to revisit museums after a major city event? In particular, this study uses the cognitive-affective-conative model, which includes the perceived value of the cognitive factor, range of affective components (Attractiveness, Fitness, Uniqueness, and Atmosphere) and the behavioural intention of museum visitors as a conative component. The study has adjusted the model to comply with the analysed literature and have developed new combinations of behavioural dimensions. It is important to understand how to gauge cognitive and affective components in order to predict visitor behaviours and their revisit intentions, as there might be various combinations of cognitive and affective components that lead to high or reversibly low intentions to revisit. Hence, the study continues by seeking to answer what levels of affective components yield to high levels of intentions to revisit? 
For the purposes of the analysing mutual influences of cognitive-affective components and answer for first research question, we used confirmatory factor analysis (CFA) as well as structural equation modelling (SEM), which highlights the most influential dimensions. Simultaneously applying the conditional inference model (CTree) as an exploratory method to test the joint effects of several affective components and for further discussion on the impact of particular levels of these components.

The research omitted satisfaction as an aggregated construct, but analysed each dimension of satisfaction separately (Attractiveness, Fitness, Uniqueness, and Atmosphere). As a result, by conducting the SEM, it was established that Attractiveness and Atmosphere are the most impactful dimensions on intentions to revisit. These finding are pioneering, as this is the first time the factors of Attractiveness and Atmosphere have been identified to be the most influential factors concerning repeat custom, especially in the context of major city events and with regards to museums.

This study adds to a growing body of literature on museum visitors' and their intention forming processes. There are several important areas where this study makes an original contribution: firstly, the study has gone some way towards enhancing our understanding of interconnections of perceived value, affective components and behavioural intentions; secondly, it has developed new combinations of dimensions, namely: Attractiveness, Fitness, Uniqueness, and Atmosphere. Lastly, this is the first study that investigates levels of affective components and utilises a conditional inference model when studying interconnections of perceived value, satisfaction and visitor revisit intentions.

The findings of this study have important implications for future museum practice and management. The practical input of the study is to develop an instrument that will allow museums to predict visitor behaviour and their intentions and expectations, thus aiding museums with future action plans on visitor retention and long-term satisfaction.

\section{Theoretical background}

\subsection{Conceptual Framework}

Museums play a huge part in the life of modern society. Nowadays it is widely accepted that museums not only preserve and exhibit the heritage but also retain a paramount role in education, social justice, integration of various social groups, creation of sense of place, transforming environment, developing public diplomacy and envoys of countries and cities in the international arena (Chiwara, 2016; Hein, 2005; Kochelyaeva 2015; Newman, McLean, Urquhart, 2005; Stylianou-Lambert et al., 2014; Ünsal, 2019). That's why long-term success and the well-being of museums are of great importance to a wide circle of stakeholders. To achieve the well-being of museums it is crucial to understand the behaviour of visitors in order to build more effective development strategies.

Museum-related events are a powerful part of museum strategy and exert significant impact on visitor behaviours (Camarero, and Garrido, 2011; Jaremen, and Rapacz, 2018). Events organized inside museums are studied more often (Barron and Leask, 2017; Choi et al., 2020), whilst joint events by museums (inter-museum events) including major city events have not enticed researchers' attention (Evans, 2012) and mainly focused on the demographic profile of visitors (Bjeljac, et al., 2011), audience development (Mavrin, and Glavaš, 2014), and visitors experiences (Germain, 2016).

One of the objective indicators of a museums' success is its repeat custom, and whether it has increased visitor retention. Researchers emphasise the value of revisits because it is significantly more cost effective to bring back a visitor rather than to attract a new one (Cossío-Silva et al., 2019). Returning visitors are a very sought-after segment for museums as well as in other industries, as these visitors are loyal, satisfied, and more inclined to spread positive word of mouth. We attempt to shine a new light 
on how major city events can influence museum visitor behaviour, particularly with regard to their intention to revisit a museum.

Consumer behaviour is the result of creating behavioural intentions to act in a certain way (Ajzen and Fishbein, 1980; Fishbein and Ajzen, 1975; Ajzen, 1991). Intention is a planned future behaviour (Oliver and Swan, 1989). 'Intentions alone should be sufficient to predict behaviour' (Ajzen, 1991: p.185). Ajzen argues 'Intentions are assumed to capture the motivational factors that influence a behaviour...As a general rule, the stronger the intention to engage in a behaviour, the more likely should be its performance' (1991, p. 181). Overall, visitor intentions are 1) an individual prerequisite of behaviour, and 2) collectively, a good indicator of an organisation potential. A number of authors have reported that behavioural intention is an important construct in museum-focused publications (Brida et al. (2012) (Museum of Modern Art), Vega-Gómez et al. (2020) (González Santana public museum), Tofighian (2015) (Rotterdamse Museumnacht)) and in event-focused publications (Kim (2014) (food festival), Osti et al. (2012), Brown et al. (2018) (sport events), Hussein (2016) (local regular event), Vesci and Botti (2019) (culinary festivals)). However, previous studies have not dealt with major city event's impact on museum visitors' behaviour.

In recent decades, there has been an increasing interest in observing visitors' behaviour through 'cognitive - affective - conative' model (Kim et al., 2010, Altunel and Erkurt, 2015; Tsaur, 2018; Cole and Illum, 2006; Agapito et al., 2013). According to this model, intention represents a conative component, which is the result of (is formed by) cognitive and affective components. Recent evidence suggests that there is a complex interconnection shared among the three components of the model (Kang et al., 2018). The cognitive component influences the affective component, but at the same time can also influence the conative component (Brown et al., 2018; Choo et al., 2016; Kang et al., 2018).

Several attempts have been made to represent the cognitive component of the model by using a perceived value construct. Perceived value is one of the key phenomenon in understanding the behaviour of customers. 'Intentions and perceptions of behavioural control should interact in the prediction of behaviour' (Ajzen, 1991: p.188). Perception has a substantial influence on satisfaction, because satisfaction is the comparison between perception and received experience (Laing et al., 2014). Applied to the events settings perceived value (as a cognitive component of the model) is important when it comes to understanding the process behind a visitor's decision-making (Kim et al., 2010). Overall, the perceived value provides a deeper understanding of consumer perception and stimulates behavioural intentions (Cronin et al., 2000). Tinashe, (2019), Kim (2014; 2010) empirically tested this influence. Perceived value of major city events can shape the behaviour of museum visitors.

Studies of consumer behaviour show the importance of affective components within the model. Affective components are immensely intricate, complex and are a popular phenomenon. Affective components have received a significant amount of attention from researchers, as they influence the conative component (intention) (Braun et al., 2014). When applied to museums and to event settings, researchers mostly study affective components represented by the 'satisfaction' construct. Previous studies have reported that satisfaction is connected to intention and represents a strong predictor of visitor revisit intention (Choo et al., 2016). Several authors have argued that the satisfaction of museum visitors represent a good foundation for increasing customer behavioural intention (Codignola and Mariani, 2017; Endah et al., 2017; Tofighian, 2015: Kang et al., 2017). However, limitations reveal that researchers have mostly ignored the impact of satisfaction on museums in the context of an event, as well as how events influence museum visitor behaviour. In addition, the dimensions of satisfaction are still debatable. Researchers have suggested different sets of dimensions to measure satisfaction as an affective part of the cognitive, namely the 'affective-conative' model. This study does not combine dimensions into the satisfaction construct. In contrast, it applies effective components without aggregation.

\subsection{Conceptualising Variables of the Model}


Researchers have long been trying to measure cognitive (represented by Perceived Value) and affective (represented by Attractiveness, Uniqueness, Atmosphere, and Fitness) components to assess factors that shape behavioural intentions (Brida et al., 2012; Brown et al., 2018; Hussein, 2016; Kim, 2014; Osti et al., 2012; Tofighian, 2015; Vega-Gómez et al., 2020; Vesci and Botti, 2019). In this study, the following variables are based upon a literature analysis.

It is important to note that this study uses a cognitive, affective, and conative model, which are applied to museums working within the major event context (Kim et al., 2010). The study does not distinguish between museums and event when considering the perceptions, affective components, and repeat custom intention. This is because it is difficult to separate and distinguish between which elements are created by museums and which are created by the event in the visitor's mind. The study has estimated that a museum incorporated into an event generates its own unique elements and is therefore seen differently by a visitor, thus influencing their satisfaction and revisit intention in an alternative way.

Insert here figure 1

Figure 1. Theoretical framework for predicting revisit intentions.

\section{Perceived value}

There are two approaches to analysing perceived value: one-dimensional and multi-dimensional. To measure perceived value more accurately researchers argue that the multidimensional approach is more relevant for a deeper understanding of processes and mechanisms behind visitor behaviour, especially in the area of museums and events, where the one-dimensional approach is too simplified (Baker and Crompton 2000; Shen, 2016). This study is modelling visitor perceived value via combination of experience and place reputation.

Experience. According to the experience economy concept customers tend to pay for an experience, rather than for a product or service (Pine and Gilmor, 1999). Researchers have underlined the value of the experience for museum visitors (Roppola, 2012; Dirsehan, 2012) and events visitors (RodriguezCampo et al., 2019). Events create a certain experience that encompasses museums participating in these events; in addition, museums can create a very new experience during an event (Codignola and Mariani, 2017). It is reasonable to expect that experience is an important dimension of perceived value that it has an influence on a visitors' affective components and has an indirect influence on conative component (on their intention to revisit).

Reputation. Perceived value includes the dimension of a reputation (Petrick and Backman 2002; Kim, 2010). There are two ways to create a reputation, the experience of previous visits and acquiring information for instance, destinations, events, and museums can build their reputations through media exposure (Li et al., 2014). Some researchers in the field of museums has empirically tested that a reputation has a significant influence on conative component (revisit intention (Zhang et al., 2018; Endah et al., 2017; Stylos et al., 2016)). In the case of events, it was noted that reputation is a part of the perceived value and has a positive effect on affective components and conative component (intention to visit or revisit (Kim et al., 2010)). In addition, if an event (including museums) builds a positive reputation, it can influence the reputation of a particular museum. The reputation of the event and the museum can therefore be linked.

H1: Perceived Value is positively related to each of the Affective components (Attractiveness, Uniqueness, Atmosphere, Fitness)

H2: Perceived Value is directly positively related to the Conative component (Intention to revisit)

H3: Perceived Value is indirectly positively related to the Conative component (Intention to revisit) 
(See figure 2)

\section{Affective Components}

Modelling jointly affective components, researchers have arrived at the idea that all of them have affective and emotional attributes (Bigné et al., 2005; Prayag et al., 2013). In the museum-event context, three items were constructed to measure affectiveness (Attractiveness, Uniqueness, Fitness) based on Tsaur et al. (2017) and Liu et al. (2017). The atmosphere dimension was added as the fourth dimension based on Shishova and Kuzmina (2016).

Attractiveness. Attractiveness is a significant stimulator intensifying an interest in the history of an event and a museum by encouraging visitors to study museums and their collections. As a result, attractiveness of museums and events increases their cultural recognition and plays an important role with regards to its visitors and increases revisit intentions (Tsaur et al., 2017; Zhang et al., 2018; Baker and Crompton, 2000).

Uniqueness. Today's visitors are interested in unique service. There is a pursuit of uniqueness. Uniqueness is an important affective attribute that stimulates revisit intentions (Liu et al., 2017). Sharpley (1994) and Tsaur et al. (2017) argue that novelty-seeking shape event attachment. Authors claim that searching for novelty including unique experiences is an important motivation, 'The unique experience, associated benefits and the positive emotive feelings... During festivals, the visit itself is a way to have novel experiences. Novel things or items attract the attention of visitors and win their recognition' (Tsaur et al., 2017: p.20). Researchers emphasize the importance of uniqueness. Uniqueness helps remove the banality, step out of everyday life; uniqueness is an affective image. Thus, the uniqueness of events and the uniqueness of museum activities during events can influence behaviour of museum visitors.

Atmosphere. Atmosphere is a vital affective attribute (Tsaur et al., 2017). The construct of 'atmosphere' as an affective component implies a significant role of emotions (Liljander and Strandvik, 1997). Undoubtedly, there is an emotional quality to appeal to, atmosphere but at the same time, visitors are left with emotions that are difficult to assess. A good indicator here is the atmosphere of a museum and event. Visitors often mention the atmosphere. The Atmosphere is expressed through individual experiences, tastes, and lifestyles of visitors Bonn et al. (2007).

Fitness. According to Liu et al. (2017) the dimension of fitness is based on the concept of compatibility by Kaplan (1995). Liu et al. (2017) applied the dimension of fitness in the context of destinations, and defined it as a visitors' sense of how well a visiting experience correlates to their self-image. By allowing visitors to be themselves, in other words, some sort of self-congruity (perceive that experiences at a destination has fitness with their own self-image, allowing them to freely be themselves in the destination by enjoying involuntary attention) (Liu et al., 2017: p.258). Indeed, when a museum and event suit a visitor's tastes, fit their spirit, and relates to their lifestyle, it increases their satisfaction and has a tremendous impact on repeat custom revisit intention.

However, according to the authors of the present article, in order to demonstrate fitness, it is not enough to simply analyse its cognitive aspects. Important components of fitness (according to the concept of comfortability) also include material attributes and physical fitness that have an immense significance on visitor satisfaction (Bigné et al., 2005; Prayag et al., 2013). When it comes to museums, Jeong and Lee (2006) stated that physical environment initiates an emotional affect and it is important for visitor satisfaction. The physical environment is also cited as a crucial factor in the study by Zhang et al. (2018) as it helps predict visitor behaviour and is associated with service quality. Thus, physical fitness is formed by the outer and inner facilities and that can be perceived and evaluated by visitors. "Museum 
visitors satisfied by physical fitness are more likely to recommend and disseminate favourable comments to others" (Zhang et al., 2018, p.25).

H4: Each of Affective components (Attractiveness, Uniqueness, Atmosphere, Fitness) is positively related to the Conative component (Intention to revisit)

Insert here figure 2

Figure 2. Hypothesis visualization.

\section{Behavioural intentions}

Traditionally, it has been argued that behavioural intentions are measured by three dimensions: revisit intention, positive word of mouth (Zeithalm et al., 1996), and a willingness to recommend (Anderson et al., 1994). This study utilizes the strongest measurement of behavioural intentions namely readiness for revisit. The other dimensions (positive word of mounth and willingness to recommend) do not require much effort from the visitor while readiness to return is much more demanding.

Authors argue that visitor satisfaction within an event can be predicted by the perceived value of the event; intention to revisit a museum or a cultural organisation can also be predicted by the perceived value of the event, and intention to revisit a museum or a cultural organisation can be predicted by satisfaction with the event.

\section{Study Design}

\subsection{Sampling and data collection}

The data source for this research is the Long Night of Museums (2019) in St. Petersburg. It is the most popular annual cultural event in Russia. More than 100000 people visited this Festival in 2019. (Gorgadze, 2019).

One of the distinguishing features of the festival is the presence of many venues, 120 cultural organisations participated in the event. When gathering a sample, this study's focus was on creating the greatest amount of diversity within its criteria. First of all, genre diversity - literature, popular science, creative space, and outdoor museums. Secondly, territorial diversity was important as well. If museums are located nearby, then they can attract visitors from one another, for instance, several new museums have been opened near the Hermitage Museum, since the Hermitage Museum is a hot spot, and visitors can visit other museums on their way to the Hermitage Museum. The study suggested that it was difficult to separate influences of physical and cognitive surroundings, both of them affecting visitors and that it would not be logical to distinguish between them.

\section{Insert here figure 3}

Figure 3. Museums, on the territory of which a visitor survey was organised.

This study is based on a quantitative data collection method. Data was collected in the Anna Akhmatova Museum, St. Petersburg Museum of Buses, Russian Railway Museum and Museum of Hygiene (Figure 3) for the entire period of the festival: from $6 \mathrm{pm}$ on the $18^{\text {th }}$ of May to $6 \mathrm{am}$ on the $19^{\text {th }}$ of May. Several 
groups of interviewers were utilized, all of which interviewed museum visitors simultaneously in all the selected territories. To achieve valid results, a respondent selection mechanism with an element of randomness was used (with step 5). There were 298 valid questionnaires collected from festival visitors.

\subsection{Measurement}

The purpose of the survey was to reveal the impact of visitors' perception (cognitive component) and the series of affective components (Attractiveness, Atmosphere, Uniqueness and Fitness) on their behavioural intentions to revisit. The behavioural intention to revisit as variable was measured by the item developed by Kim et al. (2010) and Tsaur et al. (2018). It is that the visitors' intention to revisit, which is based on one proposition: 'I would like to visit this place again after the Long Night of Museums Festival'.

Perceived value (cognitive component) was measured by Kim et al. (2010) and represents three categories of visitors based on the experience and reputation of the museum:

1. Visitors that have not been to this place before;

2. Visitors that have been previously but do not appreciate the reputation of the place;

3. Visitors that have been previously and appreciate the reputation of the place.

Affective components consist of four blocks (Attractiveness, Fitness, Uniqueness, and Atmosphere), each of which consists of several propositions. The respondents were read a statement and were asked to evaluate the degree of agreement on a scale of 1 to 4 , where 1 - completely disagree, and 4 completely agree (Table I). Being neutral was not included as an option as part of this scale, in order to persuade the respondent to make a choice and have an opinion. Moreover, for scales with a large number of points, the respondent would have to spend more time thinking. Attractiveness, Fitness and Uniqueness were measured by items developed by Liu et al. (2016). Atmosphere was measured by items from Bonn et al. (2007)

\subsection{Methods}

To answer the first research question an estimate theoretical model (Figure 1) confirmatory factor analysis (CFA) was utilised. Attraction, Fitness, Uniqueness, and Atmosphere dimensions were then used as independent variables to form a structural equation model. Both factor analysis and structural equation modelling were processed using a Stata program. From the SEM conclusions can be drawn regarding general patterns of how independent variables (cognitive and affective components) effect the participant (intention to revisit). However, the conclusion lacks definition regarding how different levels of independent variables yield to particular outcomes. Hence, in order to go deeper into pathways of relationships between the most influential components further application of the conditional inference tree is needed.

Further to address the second research question, the study widened its empirical analysis with the conditional inference tree (CTree) using R package «partykit» (Hothorn et al., 2006; Hothorn and Zeileis, 2015). This method evaluated a regression relation using binary recursive splitting in a conditional inference environment. The past decade has seen the rapid development of CTree application in many fields. A CTree was advanced (Hothorn and Zeileis, 2015) and extensively applied in social science (Rehbein et al., 2015; Rho et al., 2016; Girmanová and Gašparová, 2018). Ctree provides an exciting opportunity to advance our knowledge of consumer behaviour and identify cognitive patterns of the consumer. For example, the method serves as the basis for the analysis of brand-related social media engagement (Schivinski, 2019). 
Despite this, little progress has been made in the application of Ctree in the culture and event settings. This paper attempts to use Ctree as a predictive method to determine visitor retention in the context of multifaceted interactions. Obviously, it is impossible to cover all of the factors considered earlier in the scientific literature, and only the most influential factors were used in predicting a return visit. Unlike the SEM model, which tests the separate influence of factors, the CTree is able to test jointly effecting variables (Hothorn et al., 2006). In other words, the CTree allows for the division of one factor into several levels and identifying their influence on outcomes (Han and Kwak, 2019). For example, it allows the atmosphere to be divided into several levels (low atmosphere and high atmosphere), furthermore looking at the effect of the low levels of atmosphere in more detail. In addition, the CTree is an exploratory method that allows patterns to emerge that were not originally foreseen. Hence authors do not develop a hypothesis for CTree tasks. SEM depends on the formulation of a hypotheses by the researcher, in contrast to the CTree that is not dependent on forecasts and the position of the researcher. Using CTree, to optimize the model, leaving only the most significant variables. The independent variable being the intention to revisit, and the dependent variables are the same as in the structural model (Attraction, Fitness, Uniqueness, and Atmosphere dimensions). It is worth noting that for this model, we calculated the average values of the variables.

\section{Results}

\subsection{Empirical Model}

The CFA is applied and will form the factors for Attractiveness, Fitness, Uniqueness, and Atmosphere based on the following survey questions.

Table I. CFA for Attraction, Fitness, Uniqueness, and Atmosphere

\section{Insert here table I}

The standardised factor findings together with the corresponding p-values attributed to the Attractiveness factor formation are statistically significant. Questions 13-7 and 13-2 have the highest $\mathrm{R}$ square result, whilst for questions 13-6 and 13-15 the predicted outcome is the lowest. Overall, Attraction as a contributing factor predicts at least $72 \%$ of the overall dispersion out of all of the initial variables.

The models chi-squared is 0.183 , which indicates that the model reproduced the observed covariance of the initial questions well. The RMSEA value is 0.049 , which is lower than the cut-off value of 0.8 and together with the p-value of 0.39 indicates a good fit within the model. CFI (0.992) and TLI (0.975) are at their maximum values reaching around 1 . The standardised root of mean squared residual (SRMR) is equal to 0.022 which is below cut-off of 0.08 . Finally, the coefficient of determination is high (0.72) which therefore indicates that the model is good fit. Hence, the study concludes that the factor of Attractiveness proved most popular.

Considering Atmosphere as a factor formation, all of the questions have revealed it to be significant at high level (p-values are less than 1\% significance level). Questions 13-8 and 13-20 are the most significant ( $\mathrm{R}$ square is 0.51 ) followed by question $13-19$ which have an $\mathrm{R}$ square of 0.44 . The overall $\mathrm{R}$ square value is very high at $82 \%$, which indicates that the factor of Atmosphere is responsible for $82 \%$ of the variation in the initial data. Overall, the model proves to be an acceptable fit: RMSEA is 0.079 , which is close to the cut-off point of 0.8 , but shows a lower p-value of 0.027 . Furthermore, with a $10 \%$ significance level the study can confirm that the fit is acceptable and positive. CFI (0.94) and TLI (0.92) confirms that factor was constructed with the highest level of precision. The Coefficient of Determination (CD) is high enough (0.828) and the standardised root mean squared residual (SRMR) 
is 0.04 . In conclusion, these findings allow the study to prove that Atmosphere as a factor is compatible and a positive fit within the model.

Uniqueness as factor has also revealed to be significant. Question 13-12 were converted in an opposite scale and have been revealed to be at a 10\% significance level. The remaining two questions 13-10 and 13-14 are significant at a 1\% level. Overall, the R squared rating is lower than those found for factors Atmosphere and Attractiveness, and describe a 56\% differences in the overall dispersion. However, other measurements have been found to have acceptable values, the RMSEA is 0.081 ; CFI value is 0.91 and TLI is 0.89 . The standardised root of the mean squared residual figure (SRMR) is equal to 0.11, which is higher than the cut-off point of 0.08 . Though this factor does not reveal high levels of compatibility, the findings assume that Uniqueness as a factor is still acceptable for further predictions, as it was revealed an important factor when considered as a theoretical construct.

Considering Fitness as a factor, the study has not separated cognitive and physical dimensions; it has formed a single factor for both dimensions (considering the physical and cognitive fitness together). At the first eight questions were included as the basis for Fitness as a factor. Some of the questions were converted (questions 13-13, 13-1, 13-3, 13-5, 13-8), whilst others were included in the initial scale (questions 13-4, 13-11 and 13-9). Interestingly all of the questions revealed to be significant at a level of $10 \%$, although the $\mathrm{R}$ squared rate (1.3\%) is lower for questions 13-9 and 13-3 (R square value is 0.01 ). The most important question found was $13-11$ with an associated $\mathrm{R}$ squared rating of $58.7 \%$. Overall Fitness as a factor explains $67 \%$ of the variation. However, it was not an acceptable statistic for this set of questions and furthermore the study has excluded two questions with the lowest R squared value being questions 13-9 and 13-3.

Overall, the R squared value is high ( $67 \%$ of the overall dispersion of the initial data). However, the overall statistic was acceptable and significantly improved: the chi-squared value is 15.335 with a pvalue of 0.08 , which is higher than cut-off point of 0.05 , indicating that the model reproduced the observed covariance well. The RMSEA value is at a low level $(0.05)$ which is lower than cut-off value of 0.08 and the associated p-value of 0.44 indicates another acceptable fit. The CFI and the TLI are high showing values of 0.93 and 0.88 . The SRMS value (0.04) is twice as low as the cut-off point of 0.08 and the coefficient of determination (CD) is quite high at a value of 0.63 . Hence, the study concludes that the model fits well and is acceptable.

Cronbach's alpha of four factors has a value of 0.75 , meaning that all the factors are showing a similarity. From a theoretical perspective, this result is not surprising as Attractiveness, Atmosphere, Fitness and Uniqueness are different dimensions of the broader concept of satisfaction. As the goal is to identify the relationship between the different sub-components of satisfaction and to avoid aggregation, this study continues to analyse the four factors that have been formed previously as independent variables. The other independent variable that this study tries to control is the concept of perceived value. Perceived value is formed on the basis of an experience and its reputation, these are included in the structural model as categorical variables within these 3 levels: 1 - 'I have never been here before'; 2 - 'I have been here, but I don't like it very much'; 3 - 'I have been here before and liked it'.

As a dependent variable, the study uses behavioural intention presented by the statement asked - 'I would like to visit this place again after the Long Night of Museums event'.

Furthermore, we apply structural equation model (SEM). The SEM correlates with the associated significance values, which are presented in the diagram below. In model, it has is shown that the direct and mediate effects of the variables correlate with the theoretical model adopted by authors based on Kim et al. (2010), Tsaur et al. (2017) and Liu et al. (2017) and obtain the following path coefficients (Figure 4). 
Insert here figure 4

Figure 4. Structural Model

Note: Coefficients of models are above and below the arrows significant at 10\%; ** significant 5\%; significant at 1\%. Source: own calculations based on Survey results.

The model represents an acceptable correlation and fit: The RMSEA of 0.057 is less than the cut-off point of 0.10; The CFA (0.961) and TLI (0.930) are both close to 1; Lastly, the SRMS (standardised root mean squared residual) is 0.046 and the $\mathrm{CD}$ (coefficient of determination) is 0.193 .

As shown by the sum $0.076+0.038+0.082=0.196$, the perceived value in this case does not have an overall effect as no significant direct implications are found. However, there is a high mediation effect value of the perceived value on the four factors shown, and through this, it is shown that the perceived value does have an effect on behavioural intentions to revisit the event.

\subsection{Conditional Inference Tree}

Finally, this study has applied the Conditional Inference Tree (CTree) to reveal which levels of independent factors leads to maximum of visitor's behavioural intention to revisit the event. For the CTree construction, the same set of independent variables have been applied, and they have been tested to gauge the impact other variables, most importantly the intention to revisit.

\section{Insert here figure 5}

Figure 5. Conditional Inference Tree.

In line with SEM, the Conditional Inference Tree (Figure 5) reveals that the Atmosphere of the place is the most significant variable. Additionally, the algorithm distinguishes observations with a low Atmospheric value $(\leq 2.429)$ and a high Atmospheric value $(>2.429)$. With a low rating of Atmosphere and a low level of Attractiveness as a factor $(\leq 2.5)$, the desire to revisit the event again will be minimal $($ mean $=1.893, \mathrm{n}=28$, err $=24.7)$. However, with a high value of Attractiveness $(>2.5)$, there is a larger variation in the desire to visit again, but overall respondents are more willing to revisit (mean = 3.0, $\mathrm{n}=26$, err $=26.0$ ). Places with an Atmospheric level of $>2.429$ are divided by level of Attractiveness. Places of medium Attractiveness $(<=3.25)$ demonstrate a high degree of repeat visits, revealing a value close to the node of 4 (mean $=3.301, \mathrm{n}=83$, err $=53.5)$, and the most attractive places $(>3.25)$ provide the highest degree of repeat visits among visitors ( mean $=3.760, \mathrm{n}=125$, err $=42.8$ ).

\section{Discussion and Conclusion}

\subsection{The most impactful dimensions of the revisit intentions}

The main purpose of this study was to examine and clarify the relationship between dimensions of cognitive and affective components that have an impact on the revisit intentions of museum visitors, in the context of a major city event. Our findings suggest that there is a direct effect of affective components from a major city event that influences the revisit intention of museums visitors. In line with Tsaur et al. (2018), Chiappa and Gallarza (2014) and Liu et al. (2017) the attractiveness is an impactful dimension of revisit intention. In contrast to the earlier findings by Kim et al. (2010), which proposed that the perceived value of a major city event reveals to have significant direct effect on the intentions to revisit a museum, our study has found a significantly large indirect effect on the intention to revisit through other affective components such as attractiveness, fitness, uniqueness and atmosphere. 
Taken together, results suggest that perceived value is positively related to each of the affective components $(H 1)$. One of the more significant findings to emerge from this study is that perceived value is directly positively related to the conative component $(H 2)$. It was also shown that perceived value is also indirectly positively related to the conative component (H3). In addition, each of affective components is positively related to the conative component $(H 4)$.

Furthermore, the CTree has confirmed the SEM results and has added new insights. It shows the interactive effect of several variables. Thus, confirming that Atmosphere and Attractiveness have been proven to play the most important role. Atmosphere and Attractiveness provide the greatest influence when considering whether to revisit an event. Furthermore, the research succeeded in defining not only the significant dimensions but the most importantly the combinations of dimensions as well. The CTree shows how the intersection of several factors can predict a revisit intention. Low Atmosphere and low Attractiveness predict low level of the Retention. High Attractiveness with low Atmosphere increases the Retention rate, and only a high Atmosphere and high Attractiveness can give a consistently high Retention rate. A CTree was employed since it allows to distinguish (clusters) few groups of visitors: (1) visitors with strict intention to be back (Node 7); (2) visitors who definitely will not intend to revisit museum (Node 3); (3) visitors who are not aware of the intention to revisit (Node $4 \& 6$ ). This finding has important implications for developing strategy of the museum. From the perspective of museum management and marketing third group of visitors is the target group for museum efforts to increase visitation. Museum authorities should be focused on this particular group and the opportunity to distinguish this group is important for developing the marketing strategy.

Additionally, the current study found the compensation effect of affective dimensions. CTree provides an opportunity to identify the compensation effect of two affective dimensions Atmosphere and Attractiveness. CTree application allows to identify that for a group of visitors who are not aware of their intention to revisit, a low level of Attractiveness is compensated by the high level of Atmosphere and vice versa. This combination of findings provides some support and important insides for museum marketing strategy development. It can therefore be assumed that the Atmosphere and Attractiveness are most significant and at the same time compensated by each other dimensions for museum visitors.

There are differences and similarities compared with the study by Kim et al. (2010) unlike Kim's results this study's models (SEM and CTree) have revealed the Perceived Value to have no significant direct effect. Moreover, satisfaction was not considered as a single factor. This study has split satisfaction into four separate factors and studied their individual impact on the revisit intentions of visitors. This has made it possible to identify the most influential factors, and to demonstrate the insignificant effect of Uniqueness. On the other hand, a significant effect of Perceived Value upon all affective components have been found similarly to Kim et al. (2010). In addition, the design of this study allowed for the calculation of the cumulative effect on the revisit intentions of visitors, and the CTree has identified the most important factors for the optimal assessment of repeat custom.

\subsection{Theoretical contribution}

The findings from this study make several contributions to the current literature. The current findings add to a growing body of literature on revisit intention forming mechanisms. Taken together, the results suggest that the most influential dimensions that affect intention are attractiveness and atmosphere. These dimensions become dominant, when it comes to creating revisit intentions. The study completes the range of affective components, but unlike previous studies (Kim et al., 2010; Tsaur et al., 2018) it do not split all affective components into one single measurement of satisfaction. Most importantly the study inserts a new dimension of the affective component that has been missing in the previous pioneering studies by Kim et al. (2010) and Tsaur et al. (2018) namely atmosphere as a component has been revealed to be the most impactful among all other affective components. 
The last issue that has emerged from these findings has clarified the considerable role of context, when measuring revisit intention and the behaviour of museum visitors. The most prominent theoretical input is the role of the context. The study has gone some way towards enhancing our understanding of visitor behaviour regarding museums and events. The results of this research support the idea that there is mutual influence of the museum and event. Often behaviour inside the museum is considered, with external conditions being excluded. There are separate studies that focus on behaviour inside the event. However, these studies do not take into account the mutual influences between the event and museum themselves.

\subsection{Practical Implications}

In general, the practical implications of the results are of paramount importance for museum management, confirming beneficial effects of participation in major city events, and the role that participation has when encouraging revisits. The results have immense practical significance for museum employees. Museum managers have to appreciate that Atmosphere and that Attractiveness are the most substantial factors for visitor expectations and appear to be the most important factor in influencing their revisit intentions.

The evidence from this study suggests that museum participation in diversified and large-scale intermuseum events is beneficial. This means that events such as the Long Night of Museums should seriously be considered when defining a development strategy for a museum. Today participation in this event often feels formal, the goal is often just to be seen. It is paramount to pay attention, when creating an atmosphere and making the most of the museum's attractiveness within the Long Night of Museums. Preparations for this important event should effect all elements of the museum strategy and museum value chain: infrastructure, fundraising, programme and content development, as well as educational programme detail to name a few. It is crucial to place the importance of preparation for the Night of Museums into each listed element.

Development of a unique value proposition might be a key strategy not only for the context but also in terms of creating a unique atmosphere and a unique attractiveness. The Saint Petersburg Night of Museums has not recognised this approach yet, but it is vital one to implement.

Yet another major idea is collaborations between museums. Collaborations are mostly non-existent, with each museum developing its own programme for the Long Night of Museum independently, often unaware of the programmes of other museums. Museums need to make these joint programmes, forming strategic inter-museum alliances.

One more vital practical recommendation might be to create additional inter-museum events and intermuseum collaborations besides during the Long Night of Museum.

An appropriate example is the Long Night of Museum in Berlin that has embedded into the strategy of the development of many museums. Besides, inter-museum collaborations are prevalent amongst museums in Berlin. It is noteworthy that this approach is not widespread in Saint Petersburg. However, this study is of interest not only for Russia but for Saint Petersburg as well. The Long Night of Museum is held in 39 countries with over 2000 participating museums. Thus, suggested recommendations might be useful for a wider circle of organizations.

\subsection{Limitations}

This study was conducted only in Saint Petersburg; however, as the event is global, other cities may benefit from the findings. The study focused mainly on intensions to revisit, further study may benefit from investigating whether intentions and actions correlate and how many visitors return to the museums in the future. In addition, visitors that attended virtually were not included in the study; it may be wise to investigate further research on how museums can enhance their digital experience and 
encourage more visitors to attend events online. Furthermore, the sample was gathered by interviewing one in every five people. There was no gender or age diversification. Instead, the sample's diversification was concentrated around the type of place and area. Lastly, the research was focused around the local population and included Russian tourists primarily. This is because this particular group of visitors are thought to be the most inclined to revisit (foreign tourists are less likely to revisit considering several barriers such as visas, and the significant travel distance). However, it is a substantial limitation of the research.

\subsection{Directions for future research}

As local native speaking visitors were the only sample encouraged to take part, future research could include international visitors. This may determine whether tourists visit certain cities for the city itself or whether they visit to see the museums and events that the city holds.

As stated previously, this research has focussed on evaluating intentions, in particular the intention to revisit. An important consideration for future research would be to analyse the intentions and behaviour gap, in order to understand whether intentions to revisit materialise.

There is abundant room for further progress in determining revisit intentions based on user generated content analysis and trying to juxtapose it with the offline behaviour of customers. Further research should be done to compare visitors revisit intention in different cities and counties to identify if it is affected by local or national context. If the debate is to be moved forward, a better understanding of local and national context needs to be developed.

\subsection{Concluding Remarks}

Concerning the Covid-19 epidemic, the state of lockdown has presented museums with several new challenges. Firstly, it is necessary to understand how to operate and attract visitors under these circumstances and going forward whether it is important for museums to create a larger online presence and platform. Museums may need to evolve and innovate digitally in order to stay open and compete in an ever-changing world.

This research has proven that participation in major city events are beneficial for museums, increasing not only visitor custom but also most importantly encouraging their intention to revisit in the future. Thus, museums should take a more active part in collaborative events. Collaborations greatly affect revisit intentions and aid lesser-known museums with their promotion as well as encouraging visitors to visit museums in the same area that they may not have intended to see. If museums work together and create more collaborative 'experiences' this may aid their long-term success and development.

\section{Acknowledgements}

We would like to express our gratitude to Victor Karepin for his helpful comments in data analysis methods and Laboratory of Cultural Economics for assistance in collecting empirical data.

\section{References}

Agapito, D., Valle, P. and Mendes, J. (2013), “The cognitive-affective-conative model of destination image: A confirmatory analysis", Journal of Travel \& Tourism Marketing, Vol. 30 No. 5, pp.471-481.

Ajzen, I. (1991), "The theory of planned behavior", Organizational behavior and human decision processes, Vol. 50 No. 2, pp.179-211. 
Ajzen, I. and Fishbein, M. (1980), Understanding attitudes and predicting social behavior. Englewood Cliffs, NJ: Prentice-Hall.

Altunel, M. C. and Erkurt, B. (2015), "Cultural tourism in Istanbul: The mediation effect of tourist experience and satisfaction on the relationship between involvement and recommendation intention" Journal of Destination Marketing \& Management, Vol. 4 No. 4, pp.213-221. DOI: 10.1016/J.JDMM.2015.06.003.

Anderson, C., Rungtusanatham, M. and Schroeder, R. G. (1994), "A theory of quality management underlying the Deming management method", Academy Management Review, Vol. 19 No. 3, pp.472-509. DOI: $10.2307 / 258936$

Baker, D. and Crompton J. (2000), "Quality, Satisfaction and Behavioral Intentions", Annals of Tourism Research, Vol. 27 No. 3, pp.785-804. DOI: 10.1016/S0160-7383(99)00108-5.

Barron, P. and Leask, A. (2017), "Visitor engagement at museums: Generation Y and 'Lates events at the National Museum of Scotland", Museum Management and Curatorship, Vol. 32 No. 5, pp.473-490. DOI: 10.1080/09647775.2017.1367259

Bjeljac, Z., Brankov, J. and Lukić, V. (2011), "The Museum Night event - the demographic profile of the visitors in Serbia”, Forum Geografic, Vol. 10 No. 2, pp.229-234.

Bigné, J.E., Andreu, L. and Gnoth, J. (2005), “The theme park experience: An analysis of pleasure, arousal and satisfaction", Tourism Management, Vol. 26, pp.833-844. DOI: 10.1016/j.tourman.2004.05.006

Bonn, M. A., Joseph-Mathews, S.M., Dai, M.; Hayes, S. and Cave, J. (2007), "Heritage/Cultural Attraction Atmospherics: Creating the Right Environment for the Heritage/Cultural Visitor", Journal of Travel Research, Vol. 45, pp.345-354. DOI: 10.1177/0047287506295947.

Braun, E., Eshuis, J. and Klijn, E.-H. (2014), “The effectiveness of place brand communication”, Cities, Vol. 41, Part A, pp.64-70, DOI: 10.1016/j.cities.2014.05.007.

Brida, J. G., Meleddu, M. and Pulina, M. (2012), "Factors influencing the intention to revisit a cultural attraction: The case study of the museum of modern and contemporary art in Rovereto", Journal of Cultural Heritage, Vol. 13, pp.167-174.

Brown, G., Assaker, G. and Reis, A. (2018), "Visiting Fortaleza: Motivation, satisfaction and revisit intentions of spectators at the Brazil 2014 FIFA World Cup", Journal of Sport \& Tourism, Vol. 22 No. 1, pp.1-19. DOI: 10.1080/14775085.2017.1417889.

Camarero, C. and Garrido, M. (2011), “Strengthening Members' Relationships Through Cultural Activities in Museums", Journal of Leisure Research, Vol. 43 No. 4, pp.560-588.

Chiwara, D. (2016), "Fostering human rights and empowering communities through art and education: The case of the National Gallery of Zimbabwe", Museum International, Vol. 68 No. 3-4, pp.164-175.

Choi A., Berridge G., Kim C. (2020), “A Study on Classifying Visitors' Types by Motivations of Museum Late Events: Focused on Museums", Sustainability Vol.12 No. 22 pp. 1-18. 9382. DOI: $10.3390 /$ su12229382.

Choo, H., Ahn, K. and F. Petrick, J. (2016), “An integrated model of festival revisit intentions: Theory of planned behavior and festival quality/satisfaction", International Journal of Contemporary Hospitality Management, Vol. 28 No. 4, pp.818-838. DOI: 10.1108/IJCHM-09-2014-0448. 
Codignola, F. and Mariani P., (2017), "Location Attractiveness as a Major Factor in Museum Visitors Choice and Satisfaction", Management Studies, Vol. 5 No. 2, pp.75-90. DOI: 10.17265/23282185/2017.02.001.

Cole, S. T. and Illum, S. F. (2006), "Examining the mediating role of festival visitors' satisfaction in the relationship between service quality and behavioral intentions", Journal of Vacation Marketing, Vol. 12 No. 2, pp.160-173.

Cossío-Silva, F. J., Revilla-Camacho, M. Á. and Vega-Vázquez, M. (2019), “The tourist loyalty index: A new indicator for measuring tourist destination loyalty?", Journal of Innovation \& Knowledge, Vol. 4 No. 2, pp.71-77.

Cronin, J. Joseph, Michael, K., and G.Tomas. M Hult. (2000), “Assessing the Effects of Quality, Value, and Customer Satisfaction on Consumer Behavioral Intentions in Service Environments", Journal of Retailing, Vol. 76 No. 2, pp.193-218. DOI: 10.1016/S0022-4359(00)00028-2.

Del Chiappa, G., Andreu, L. and Gallarza, M. G. (2014), "Emotions and visitors' satisfaction at a museum", International Journal of Culture, Tourism and Hospitality Research, Vol. 8 No. 4, pp.420-431. DOI: 10.1108/IJCTHR-03-2014-0024.

Dirsehan, T. (2012) "Analyzing museum visitor experiences and post experience dimensions using SEM" Bogazici Journal: Review of Social, Economic \& Administrative Studies, Vol. 26, pp.103-125. DOI: 10.21773/boun.26.1.6

Endah, P. E., Umar, N., Suharyono, S. and Andriani, K. (2017), "Study on destination image, satisfaction, trust and behavioral intention", Russian Journal of Agricultural and SocioEconomic Sciences, Vol. 61 No. 1, pp.148-159 DOI: 10.18551/rjoas.2017-01.15.

Evans, G. (2012), "Hold Back the Night: Nuit Blanche and All-Night Events in Capital Cities", Current Issues in Tourism, Vol. 15 No. 1/2. pp.35-49. DOI: 10.1080/13683500.2011.634893

Fishbein, M. and Ajzen, I. (1975), Belief, attitude, intention and behavior: An introduction to theory and research. Reading, Massachusetts: Addison-Wesley.

Germain, F. (2016), "Visiting museum at night: A decidedly different experience", Loisir et Société / Society and Leisure, Vol. 39 No. 3, pp.433-450. DOI: 10.1080/07053436.2016.1244146

Gil, S. M. and Ritchie, J. R. (2009), "Understanding the museum image formation process: A comparison of residents and tourists", Journal of Travel Research, Vol. 47 No.4, pp.480-493 DOI: $10.1177 / 0047287508326510$.

Girmanova, L. and Gašparová, Z. (2018), “Analysis of data on staff turnover using association rules and predictive techniques", Quality Innovation Prosperity, Vol. 22 No. 2, pp.82-99 DOI: 10.12776/qip.v22i2.1122.

Gorgadze, A. (2019), "Digital Footprint of Cultural Events: The Case of Museum Night in Russia", In International Conference on Digital Transformation and Global Society. Fourth International Conference, DTGS 2019, St. Petersburg, Russia, June 19-21, 2019, pp.422-431, DOI: $10.1007 / 978-3-030-37858-5 \_35$.

Han, H. and Kwak, M. (2019), "An alternative method in estimating propensity scores with conditional inference tree in multilevel data: A case study", The Korean Data \& Information Science Society, Vol. 30 No. 4, pp.951-966 DOI: 10.7465/jkdi.2019.30.4.951.

Hein, G. E. (2005), "The role of museums in society: Education and social action" Curator, Vol. 48 No. 4, pp.357-363. DOI: 10.1111/J.2151-6952.2005.TB00180.X 
Hothorn, T. and Zeileis, A. (2015). "partykit: A modular toolkit for recursive partytioning in R", The Journal of Machine Learning Research, Vol. 16 No. 1, p.3905-3909.

Hothorn, T., Hornik, K. and Zeileis A. (2006), “ctree: Conditional Inference Trees”, Vignette R package partykit version 1.1-1.

Hussein, A. S. (2016), "How event awareness, event quality and event image creates visitor revisit intention? A lesson from car free day event", Procedia Economics and Finance, Vol. 35, pp.396-400. DOI: 10.1016/S2212-5671(16)00049-6.

Jaremen, D.E. and Rapacz, A. (2018), "Cultural events as a method for creating a new future for museums", Turyzm/Tourism, Vol. 28 No. 1, pp.25-33. DOI: 10.18778/0867-5856.28.1.11

Jeong, J.H. and Lee, K.H. (2006), "The physical environment in museums and its effects on visitors' satisfaction", Building and Environment, Vol. 41 No. 7, pp.963-969.

Juniu, S. (2009), “The transformation of leisure”, Leisure/Loisir, Vol. 33 No. 2, pp.463-478.

Kang, J. H., Jang, J. C. and Jeong C. (2018), "Understanding museum visitor satisfaction and revisit intentions through mobile guide system: moderating role of age in museum mobile guide adoption", Asia Pacific Journal of Tourism Research, Vol. 23 No. 2, pp.95-108, DOI: 10.1080/10941665.2017.1410190

Kaplan, S. (1995), "The Restorative Benefits of Nature: Toward an Integrative Framework", Journal of Environmental Psychology, Vol. 15 No. 3, pp.169-182. DOI: 10.1016/0272-4944(95)900012.

Kim, Y. H., Duncan, J. L. and Jai, T.-M. (2014), "A case study of a southern food festival: Using a cluster analysis approach", Anatolia: An International Journal of Tourism and Hospitality Research, Vol. 25 No. 3, pp.457-473 DOI: 10.1080/13032917.2014.912245.

Kim, Y. H., Kim, M., Ruetzler, T. and Taylor, J. (2010), “An examination of festival attendees' behavior using SEM", International Journal of Event and Festival Management, Vol. 1 No. 1, pp.86-95. DOI: $10.1108 / 17852951011029324$.

Kochelyaeva, N. (2015), Social and Educational Role of Museums in Promoting the Principles of the UNESCO Convention on the Protection and Pro-motion of the Diversity of Cultural Expressions. Russian Committee of the International Council of Museums: Moscow

Komarac T., Ozretić Došen D. and Jurić Bulatović V. (2019), "The role of special event in attracting museum visitors and popularizing museums", ToSEE - Tourism in Southern and Eastern Europe, Vol. 5, pp.375-387. DOI: 10.20867/tosee.05.38.

Laing B. Y., Mangione C. M., Tseng C.-H., et al. (2014), "Effectiveness of a smartphone application for weight loss compared with usual care in overweight primary care patients", Annals of Internal Medicine, Vol.18 No. 161, pp.5-12. DOI: 10.7326/M13-3005.

Li, H., Song, W. and Collins, R. (2014), "Post-event visits as the sources of marketing strategy sustainability: a conceptual model approach", Journal of Business Economics and Management, Vol. 15 No. 1, pp.74-95. DOI: 10.3846/16111699.2012.701229

Liljander, V. and Strandvik, T. (1997), "Emotions in service satisfaction", International Journal of Service Industry Management, Vol. 8 No. 2, pp.148-169.

Liu, C. R., Y. C. Wang, W. S. Huang, and S. P. Chen (2017), "Destination Fascination: Conceptualization and Scale Development", Tourism Management, Vol. 63, pp.255-267. DOI: 10.1016/J.TOURMAN.2017.06.023. 
Mavrin, I. and Glavaš, J. (2014), "The Night of the Museums event and developing new museum audience - Facts and misapprehensions on a cultural event", Interdisciplinary Management Research, Vol. 10, pp.265- 274.

Newman, A., McLean, F. and Urquhart, G. (2005), "Museums and the active citizen: Tackling the problems of social exclusion", Citizenship Studies, Vol. 9 No. 1, pp.41-57.

O’Donnell, A. W. and Barber, B. L. (2021), “Ongoing engagement in organized activities may buffer disadvantaged youth against increasing externalizing behaviors", Journal of Leisure Research, Vol. 52 No 1, pp.22-40.

Oliver, R.L. and Swan, J.E. (1989), "Consumer Perceptions of Interpersonal Equity and Satisfaction in Transactions: A Field Survey Approach", Journal of Marketing, Vol. 53 No. 21. DOI: $10.2307 / 1251411$.

Osti, L. , Disegna, M. and Brida, J. (2012), "Repeat visits and intention to revisit a sporting event and its nearby destinations", Journal of Vacation Marketing, Vol. 18. No. 1, pp.31-42. DOI: $10.1177 / 1356766711428803$.

Petrick, J., and Backman S. (2002), "An Examination of the Construct of Perceived Value for the Prediction of Golf Travelers Intentions to Revisit", Journal of Travel Research, Vol. 41 No. 1, pp.38-45.

Pine, J. P. and Gilmore, J. H. (1999), The experience economy: work is theatre and every business a stage: goods \& services are no longer enough. Harvard Business School Press, Boston.

Prayag, G., Hosany, S. and Odeh, K. (2013), "The Role of Tourists' Emotional Experiences and Satisfaction in Understanding Behavioral Intentions", Journal of Destination Marketing \& Management, Vol. 2, pp.118-127. DOI: 10.1016/j.jdmm.2013.05.001

Rehbein, F., Kliem, S., Baier, D., Mößle, T. and Petry, N. M. (2015), "Prevalence of internet gaming disorder in German adolescents: Diagnostic contribution of the nine DSM-5 criteria in a state-wide representative sample", Addiction, Vol. 110 No. 5, pp.842-851 DOI: 10.1111/add.12849.

Rho, M. J., Jeong, J. E., Chun, J. W., Cho, H., Jung, D. J., Choi, I. Y. and Kim, D. J. (2016), "Predictors and patterns of problematic Internet game use using a decision tree model", Journal of behavioral addictions, Vol. 5 No. 3, pp.500-509 DOI: 10.1556/2006.5.2016.051.

Rodríguez-Campo, L., Alén-González, E., Antonio Fraiz-Brea, J. and Louredo-Lorenzo, M. (2019), “A holistic understanding of the emotional experience of festival attendees", Leisure Sciences, pp.1-19. DOI: 10.1080/01490400.2019.1597790

Roppola, T. (2012). Designing for the Museum Visitor Experience, Routledge, UK.

Saha, P. and Nath, A. (2017), “A Conceptual Framework of Festival Visitors' Behavioral Intentions”, In MIC 2017 Conference Proceedings.

Saleem, A., Ghafar, A., Ibrahim, M., Yousuf, M. and Ahmed, N. (2015), "Product perceived quality and purchase intention with consumer satisfaction", Global journal of management and business research. Vol. 15 No. 1-E, pp.21-28.

Schivinski, B. (2019), "Eliciting brand-related social media engagement: A conditional inference tree framework", Journal of Business Research. DOI: 10.1016/j.jbusres.2019.08.045.

Sharpley, R. (1994), Tourism, Tourists \& Society, ELM, Huntingdon. 
Shen, Ye. (2016), "Perceived value in tourism experience", Travel tourism Research Association: Advancing Tourism Research Globally. 8.

Shishova E. and Kuzmina K., A. (2016) "Atmospherics measurement: the ways to make public goods available", Proceedings of the $20^{\text {th }}$ International Conference Current Trends in Public Sector Research 2016. Brno: Masaryk University.

Stylos, N., Vassiliadis, C. A., Bellou, V. and Andronikidis, A. (2016), "Destination images, holisticimages and personal normative beliefs: Predictors of intention to revisit a destination", Tourism Management, Vol. 53, pp.40-60. DOI: 10.1016/J.TOURMAN.2015.09.006

Tinashe Ch. (2019), "Data on the relationship between traveler perceived value and traveller intention to revisit a destination", University of Pretoria, South Africa.

Tofighian, N. (2015), "A study of factors which drive consumer intentions to revisit Rotterdam museumnacht”, Institution: Erasmus University Rotterdam (EUR). Financial Economics. DOI: http://hdl.handle.net/2105/18250.

Tsaur, S.-H., Wang, Y.-C., Liu, C.-R. and Huang, W.-S. (2019), "Festival attachment: antecedents and effects on place attachment and place loyalty", International Journal of Event and Festival Management, Vol. 10 No. 1, pp.17-33. DOI: 10.1108/IJEFM-02-2018-0014.

Ünsal, D. (2019), "Positioning museums politically for social justice", Museum Management and Curatorship, Vol. 34 No. 6, pp.595-607.

Vega-Gómez, F. I., Miranda González, F. J., Chamorro Mera, A. and Pérez-Mayo, J. (2020), "Antecedents of Entrepreneurial Skills and Their Influence on the Entrepreneurial Intention of Academics", SAGE Open, Vol. 10 No. 2. DOI: 10.1177/2158244020927411.

Vesci, M. ve Botti, A. (2019), "Festival quality, theory of planned behavior and revisiting intention: Evidence from local and small Italian culinary festivals", Journal of Hospitality and Tourism Management, Vol. 38, pp.5-15. DOI: 10.1016/j.jhtm.2018.10.003.

Williams, D.R. (2002), "Leisure identities, globalization, and the politics of place", Journal of Leisure Research, Vol. 34 No. 4, pp.351-368.

Zeithalm, V., Berry, L. and Parasuraman, A. (1996), "The behavioral consequences of service quality", Journal of Marketing, Vol. 60 No.2, pp.31-46. DOI: 10.2307/1251929

Zhang, H., Chang, P.H., Tsai, M.F. (2018), “How Physical Environment Impacts Visitors' Behavior in Learning-Based Tourism-The Example of Technology Museum", Sustainability Vol. 10, pp.3880 DOI: 10.3390/su10113880.

Zhang, H., Wu, Y. and Buhalis, D. (2018), "A model of perceived image, memorable tourism experiences and revisit intention", Journal of Destination Marketing \& Management, Vol.8, pp.326-336. DOI: 10.1016/j. jdmm.2017.06.004. 